\title{
Effect of Near-Wave Field Mining Tremors on the Rock Bolt Support Behaviour within Stress Domain
}

\author{
Witold Pytel $^{1, *}$, Krzysztof Fuławka ${ }^{1}$, and Piotr Mertuszka ${ }^{1}$ \\ ${ }^{1}$ KGHM CUPRUM Ltd. Research \& Development Centre, 2-8 Sikorskiego, 53-659 Wrocław, Poland
}

\begin{abstract}
One of the most serious hazard in the underground copper mining in Poland is the roof fall hazard. The scale and intensity of this type of events depends on several factors. Due to seismic activity, weaker roof strata can loosen and deform, generating additional load on the rock bolt support. The type of load depends strictly on the course of stratum deformation as well as on the intensity of the dynamic effect in the form of a seismic wave. Continuous monitoring is then necessary to determine the risk level of stability loss within existing excavations in order to minimize the probability of serious accidents. The following study analyses the impact of tremors recorded within the near-wave field upon the stress change in the instrumented rock bolts.
\end{abstract}

\section{Introduction}

Increasing the mined-out area as well as the depth of exploitation and the development of mining works near the fault zones influences the level of seismicity in Polish copper mines. The large number of tremors induced by mining activity results in rockbursts, roof falls and stress relief within active excavations and thus poses a significant safety hazard. As Korzeniowski pointed out $[1,2]$, the scale of roof deflection, associated with the formation of the destressed zone, can be a measure of the instability risk as well as the occurrence of roof collapses and roof falls. It means, that early assessment of roof fall hazard should be based on a continuous measurement of stress changes in the direct roof of mining excavations. Currently in the mines belonging to KGHM, most of excavations are secured using the rock bolt support. For cracked rocks with low strength parameters, in the zone of tectonic disturbances or hard rocks surrounding mining chambers intended for long-term use, resin or cement-grouted rock bolts are used. Due to geomechanical and economic reasons, these type of rock bolts are currently the most commonly used type of support. For rocks with medium and high strength parameters, expansion rock bolts are used [3]. These rock bolts can be applied as an individual or additional roof support for underground drifts. Locally, in the case of low strength parameters of rocks or in the junctions, cable bolts are utilized [3]. Due to the above, the monitoring of excavation stability in Polish copper mines is carried out mainly in the aspect of interaction assessment of the rock bolt support with

\footnotetext{
*Corresponding author: wpytel@cuprum.wroc.pl
} 
the rock mass [4]. The scope of the monitoring, among other things, includes observations of spalling within the direct roof stratum [2], measurements of excavation convergence [6, $7,8]$, endoscopic testing $[9,10]$, instrumented rock bolts [11] and analysis of the borehole deformation using special sensors for vertical and horizontal holes $[12,13]$.

Based on many years of experience, it should be stated that the methods applied do not fully meet the expectations regarding early warnings of instability occurrences [14], which therefore results in a relatively high number of roof falls. Example of stability loss within the direct roof is shown in Fig. 1.

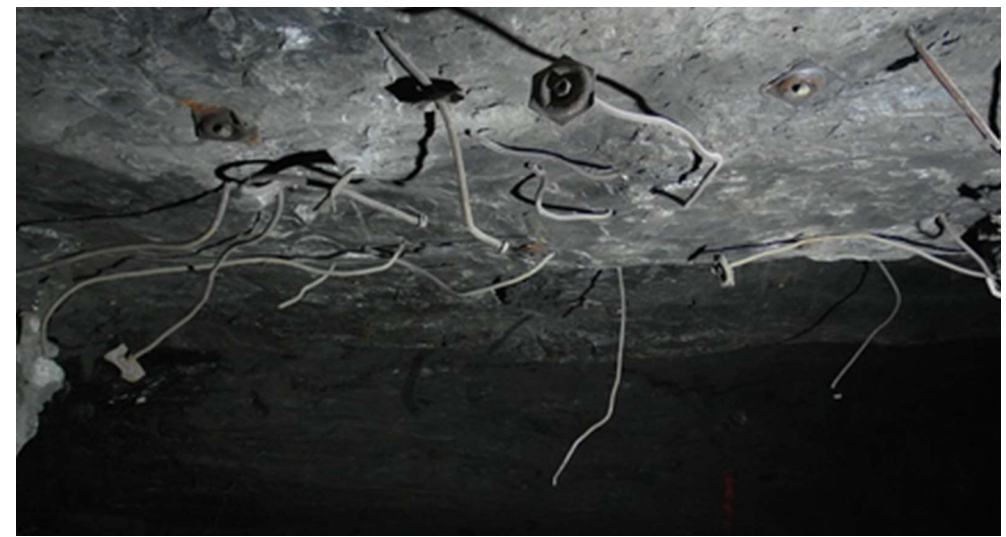

Fig. 1. Result of roof instability occurrence.

Taking into account the geomechanical conditions and the adopted mining system, it is not possible to completely eliminate tremors and dynamic events. The experience of mining around the world shows that roof falls are usually preceded by a sudden increase in axial (vertical) stresses $[15,16]$. In addition, high-value horizontal stresses may occur $[17,18]$. Stress changes are mainly associated with the occurrence of dynamic interactions generated by high-energy tremors. Bearing in mind that so-called low-energy tremors, i.e. those with energy lower than $10^{5} \mathrm{~J}$, which occurs more frequently than high-energy one, considering the possibility of their negative impact on the excavation conditions is reasonable.

One of the tools enabling precise measurement of stresses in the rock mass surrounding the excavations is an instrumented rock bolt that utilizes the strain gauge technology [19]. The following paper presents an analysis of the impact of paraseismic tremors recorded in a near field on the stress changes inside the rock bolt rods.

\section{Material and Methods}

The measurements were developed using an instrumented rock bolt $[14,19]$. This type of device allows to measure stresses on five measurement levels in four perpendicular directions. It enables full mapping of forces acting in the vertical and horizontal directions (Fig. 2).

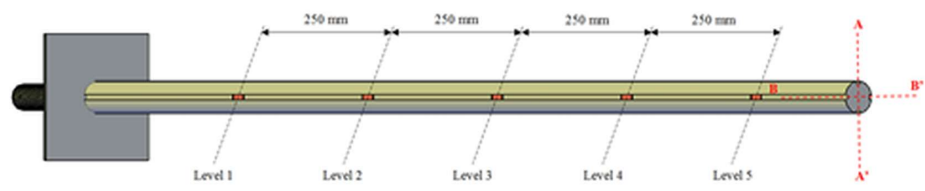

Fig. 2. Scheme of the applied instrumented rock bolt. 


\subsection{Calibration of measurement system}

In order to determine the relation of resistance of strain gauges on the tensile load, calibration of the measuring rock bolts in laboratory conditions with the use of a universal testing machine was carried out. The measured value of the sensor resistance $\left(R_{0}\right)$ is proportional to the specific resistivity and the length of the conductor $l_{0}$, and inversely proportional to its cross-section $A_{0}$ :

$$
R_{0}=\frac{\rho \cdot l_{0}}{A_{0}}
$$

Strain gauge measurements are based on the recording of conductor resistance changes resulting from changes in its cross-sectional area caused by tension or compression. This load causes a change in resistance $\left(R_{1}\right)$, which can be described by the following equation:

where:

$$
R_{1}=\frac{\rho \cdot l_{1}}{A_{1}}
$$

$\rho$ - specific resistance of the conductor, $\Omega \cdot \mathrm{m}$,

$\mathrm{l}_{1}-$ the length of the stretched/compressed conductor, $\mathrm{m}$,

$\mathrm{A}_{1}$ - cross-section area, $\mathrm{m}^{2}$.

Based on Hooke's law:

and

$$
l_{1}=l_{0}\left(1+\varepsilon_{x}\right)
$$

where:

$$
A_{1}=A_{0}\left(1-v \varepsilon_{x}\right)^{2}
$$

$v$ - Poisson's ratio,

$\varepsilon_{x}$ - conductor deformation, $\mathrm{m}$

Since the resistance increment $(\Delta \mathrm{R})$ is equal to:

its relative increment (change) is as follows:

$$
\Delta R=R_{1}-R_{0}
$$

$$
\frac{\Delta R}{R_{0}}=\frac{R}{R_{0}}-1=\frac{\rho l_{0}\left(1+\varepsilon_{x}\right)}{A_{0}\left(1-v \varepsilon_{x}\right)^{2}} \frac{A_{0}}{\rho l_{0}}-1=\frac{1-1+\varepsilon_{x}+2 v \varepsilon_{x}-v^{2} \varepsilon_{x}^{2}}{1-2 v \varepsilon_{x}-v^{2} \varepsilon_{x}^{2}} \approx \frac{(1+2 v) \varepsilon_{x}}{1} \approx k \varepsilon_{x}
$$

where: $k$ is a tensometric constant which value differs for various materials.

Calibration of measuring systems in laboratory conditions indicated that the increase of load applied during the tensile test at the level of $1 \mathrm{kN}$ in the elastic range corresponds to the increase of 176 units registered with strain gauge with a precision of $+/-5 \%$. Knowing the dimensions of the cross-section of the bolt rod, the normal stress $\left(p_{(k, j)} I\right)$ in the elastic deformation of the " $k$ " strain gauge installed in the cross-section " $j$ " can be calculated from the following relationship:

where:

$$
p_{(k, j) I}=\Delta \theta_{(k, j)} \cdot \frac{\xi}{A}=\Delta \theta_{(k, j)} \cdot \frac{0.0057}{1000 \cdot A}[\mathrm{MPa}]
$$

$\xi$ - proportionality factor determining the relationship between the axial load in the $j$ section and the increase of the indications on the strain gauge $(k, j)$, obtained on the basis of the calibration of the strain gauges.

When the elastic limit of the rod is exceeded, the tension stabilizes temporarily and changes from elastic to plastic behaviour (Stage II in Fig. 3). In this state the stresses are determined by the following relation: 


$$
p_{(k, j) I I}=4 \cdot 10^{-15} \cdot \Delta \theta_{(k, j)}+408.68[\mathrm{MPa}]
$$

After exceeding the lower yield point, step III introduces, in which the nonlinear deformation begins. It may be described by the following relation:

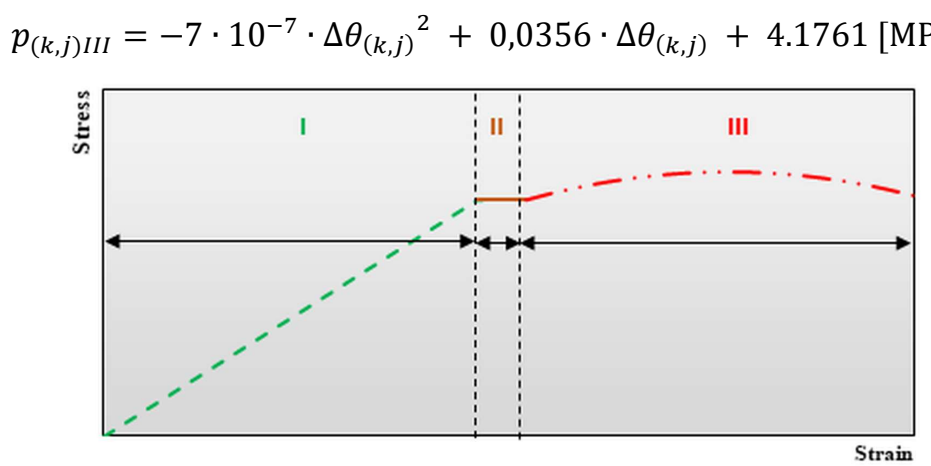

ig. 3. A typical stress-strain curve of steel used to rock bolt manufacture.

Within the research framework, three rock bolts were used for underground tests. Each bolt was calibrated on a testing machine prior to testing. Calibration results serve as a basis for the analysis of underground measurements.

\subsection{Description of the testing site}

The measurements were carried out in selected mining panel of the Lubin mine, Poland, in which the seismic activity remains relatively high. The room-and-pillar system with roof deflection was applied. Extraction of deposit in room-and-pillar systems is based on making rooms and chambers. Technological pillars are left between selected workings, with the aim to maintain the roof stability. With the progress of the mining front, technological pillars are partially extracted to remnant dimensions.

This allows for the controlled roof deflection in similar way as backfill do in other mining systems. Parameters of the roof strata, determined in accordance with the internal instructions for the rock burst hazard assessment in the Polish copper mines were [20]:

- Compressive strength Rc = 129.0 MPa,

- Energetic index of rock propensity to bursts Wet $=5.01$,

- Coefficient of tectonic roof engagement $\mathrm{M}=0.68$,

- Roof stability ratio $\mathrm{Lt}=19.3$.

Roof strata in the area of underground tests was characterized by diversified strength and composition. The roof layers have a variable tendency to spalling. This hazard was particularly high within mined out zone.

\section{Underground tests}

There were several dozen high energy events within the analysed mining panel in 2015, of which four caused damage to the excavations. In the first quarter of 2016, the level of hazard indicated an upward trend revealing a possible increase of the dynamic effect on the stability of the roof over considered area. On 17 May 2016, in the roof of three parallel drifts located between the two active mining fronts, measuring rock bolts were installed (Fig. 4). Relatively short distance between the individual bolts, not exceeding 40 meters, allowed to determine, how the epicentres' distance of tremor affects the stress state within the immediate roof strata. 


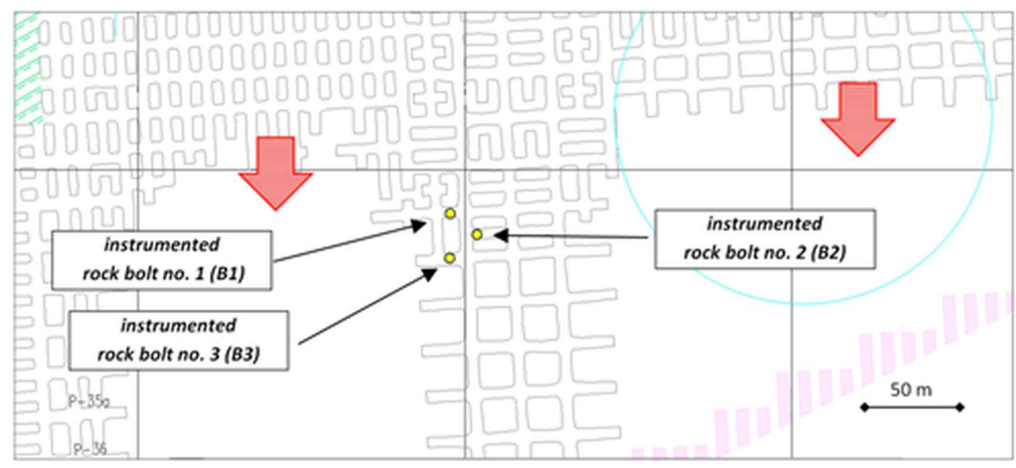

Fig. 4. Location of instrumented rock bolts (state of excavations on the day of installation).

The rock bolts were installed close to walls within the roof of the excavations. It allows to prevent their possible damage by any mining machines (Fig. 5). The rod of the measuring bolts had same external dimensions as the dimensions of standard rock bolts used to support the drifts, thus their installation was carried out in accordance with the procedure adopted.

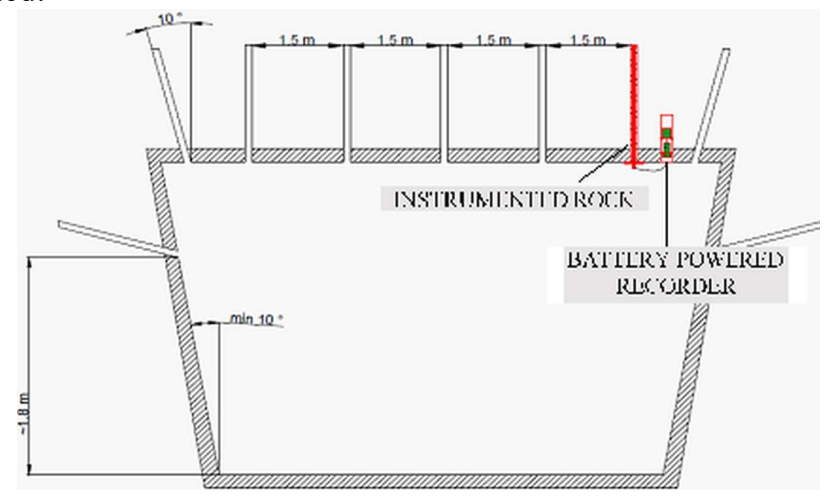

Fig. 5. Location of the instrumented bolts in the section of the drift.

The recorder was placed in a bore located approximately $30 \mathrm{~cm}$ from the measuring bolt (Fig. 6). The measuring system was equipped with power supply unit in the form of a Ni$\mathrm{Cd}$ battery and internal memory. The sampling frequency of $1 \mathrm{~Hz}$ allowed for the precise mapping of forces acting on the bolt rod.

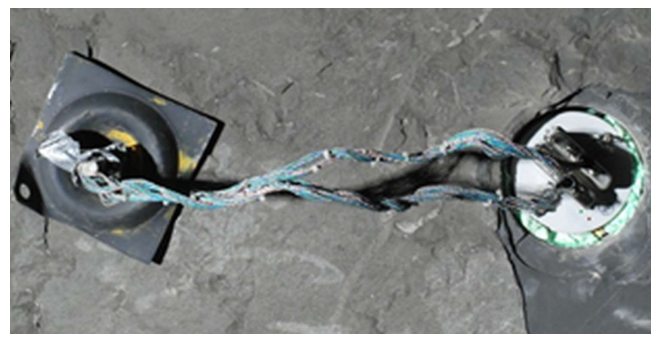

Fig. 6. View of the measuring system installed in the direct roof. 
During the measurement period, from 17 May 2016 to 10 December 2016, seismic activity remained at a high level. The energy distribution of seismic tremors in the analyzed panel is presented in Figure 7.

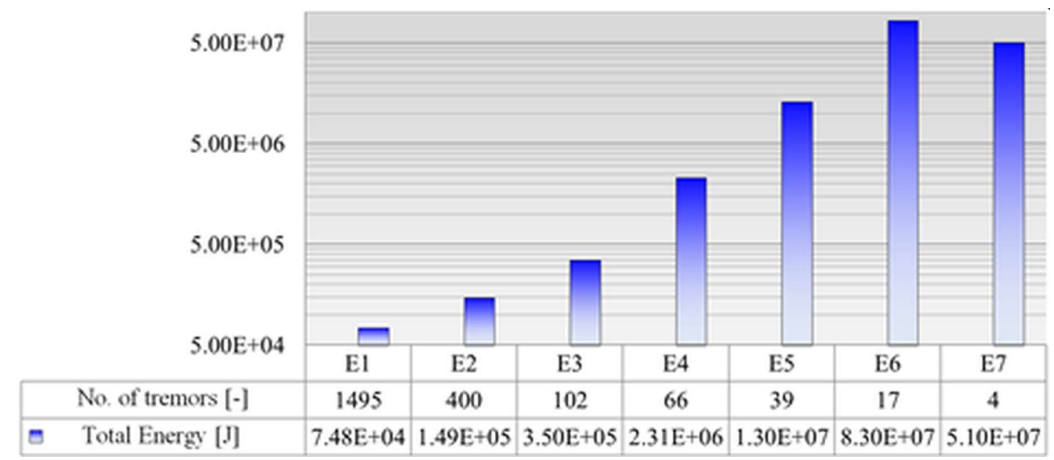

Fig. 7. Energy distribution of seismic events within the analysed period.

The total number of tremors in the abovementioned period amounted to 2123 with a total energy emission of $1.5 \times 10^{8} \mathrm{~J}$. Data of all events that caused a visible change in the stress in the bolts rods were considered.

\section{Analysis of results}

Records obtained from the measurements were analysed and correlated with the observed seismic activity within the considered mining panel in order to determine their impact on the roof condition. The recorded values of shear and axial stresses are presented in Figures $8-10$.

Despite close distance between the individual bolts, the obtained values of axial stresses on subsequent bolts differ significantly. In the bolt no. 2, axial forces exceeded the value of $450 \mathrm{MPa}$, which indicates that the bolt rod reached already a plastic state. Continuous recording allowed to register a sudden increase in axial stresses, as a result of which, 7 days before the roof collapse, the roof fall hazard was determined. On 15 June 2016, the roof was scaled due to the serious hazard of roof fall. Therefore, in the following testing period, i.e. from 16 June 2016 to 10 December 2016, the measurements were carried out using two other bolts. From figure 10 on may conclude, that on the final day of the measurements, the axial stresses in bolt no. 1 slightly exceeded the level of $100 \mathrm{MPa}$ while in the bolt no. 3 $40 \mathrm{MPa}$. 

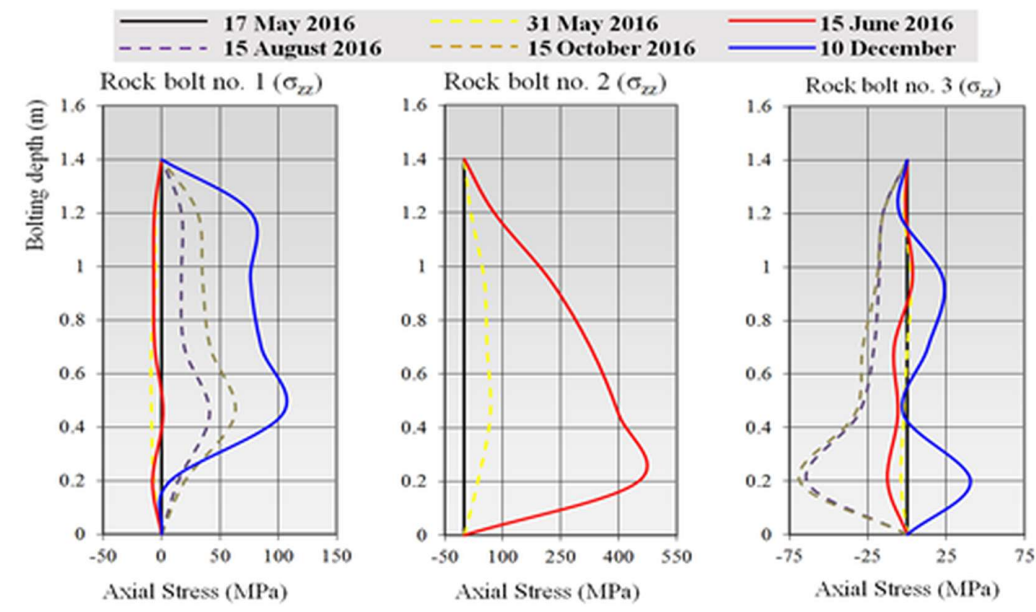

Fig. 8. Measured values of axial stresses within the direct roof.

The four-way system allowed to determine the shear stresses at each measurement level. As shown in Figures 11 and 12, the largest values of shear forces towards the $\mathrm{x}$ and $\mathrm{y}$ components varies between 0 and $1.2 \mathrm{MPa}$. It proves almost no shearing in the surrounding roof.
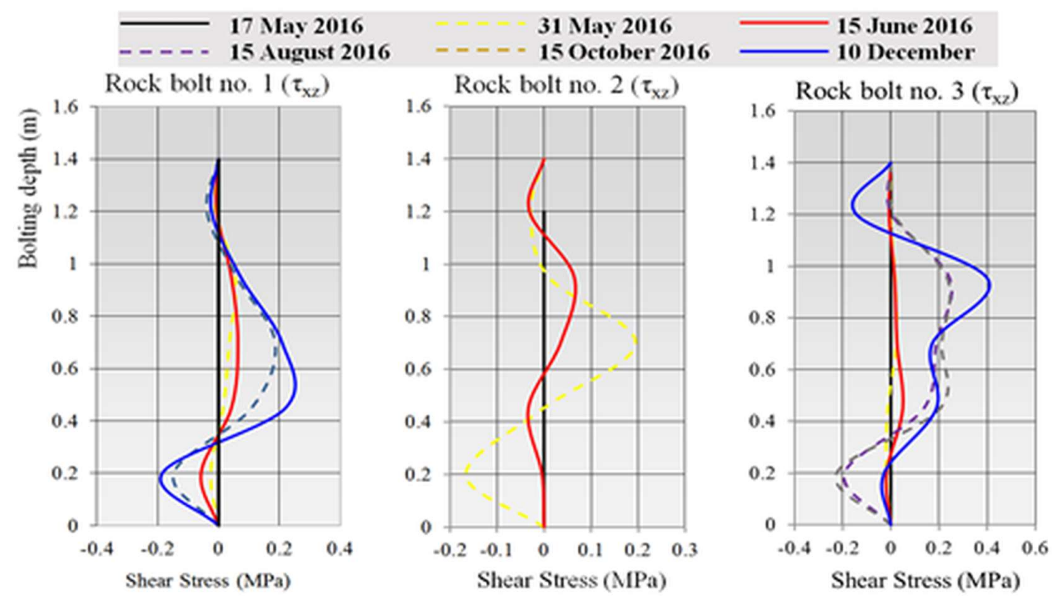

Fig. 9. Measured shear stresses $\tau_{\mathrm{xz}}$ in the roof strata. 


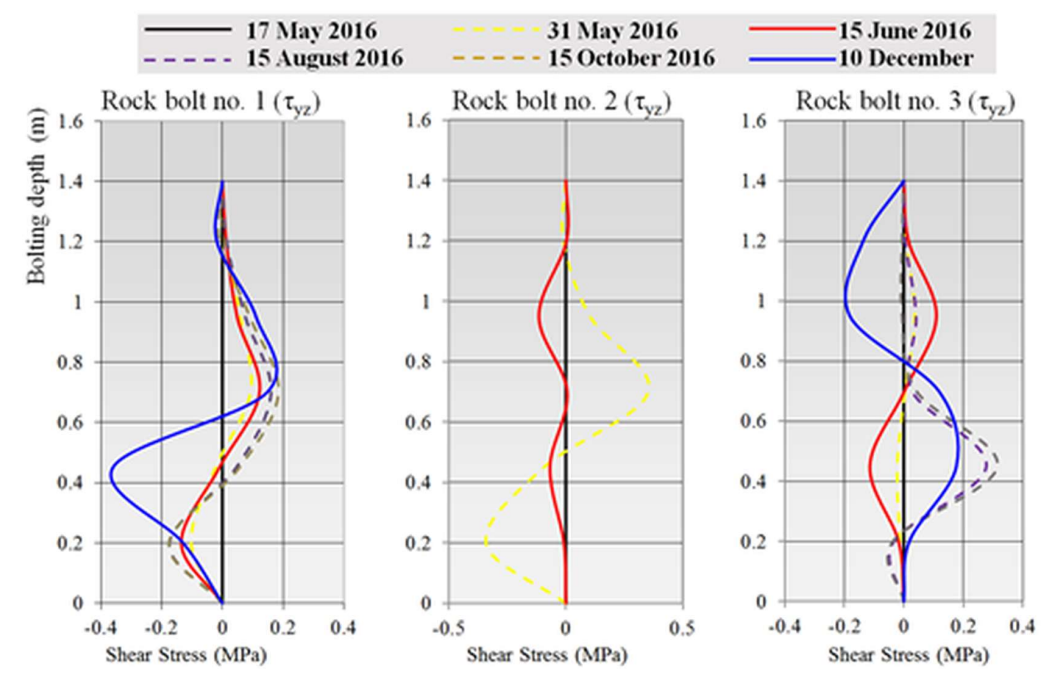

Fig. 10. Shear stresses $\tau_{\mathrm{yz}}$ in the roof strata.

\subsection{Analysis of stress changes reduced after seismic event}

Knowing the values of shear stresses $\left(\tau_{x z}, \tau_{y z}\right)$ and axial stresses $\left(\sigma_{z z}\right)$ acting upon the bolt rod, based on the Huber-von Mises criteria, the complex stress state $\left(\sigma_{\text {red }}\right)$ was reduced according to the following relationship:

$$
\sigma_{\text {red }}=\sqrt{\sigma_{z z}^{2}+\left(\sqrt{\tau_{x z}^{2}+\tau_{y z}^{2}}\right)^{2}}
$$

This enables to compare the measured values with the basic material constants. Reduced stress values were calculated for 103 events, including 60 high-energy events, for bolt no. 1 and no. 3 and 23 for bolt no. 2. Then, the results of the recorded stresses before and after the tremor were compared, allowing to verify the extent to which events of individual energy classes impacted the local roof stability (Fig. 11). Thus, all tremors which led to a visible change in the bolt stress were taken into account.

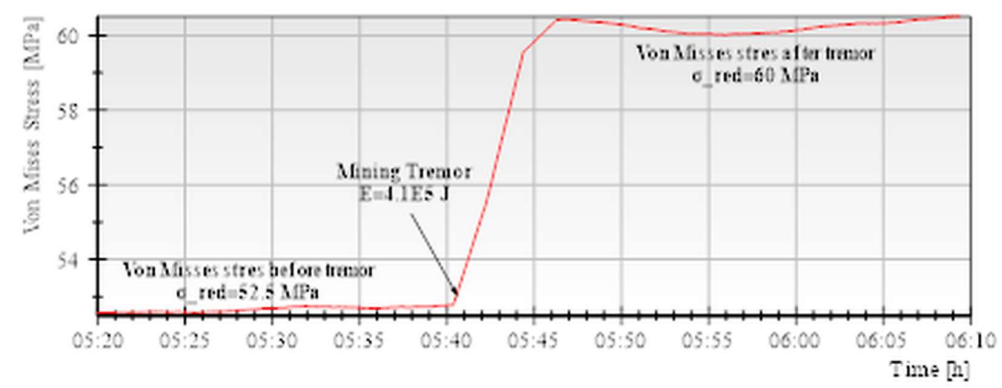

Fig. 11. Methodology for determining changes in axial stresses due to tremor.

In the bolt rod no. 1 on the experimental completion day, the maximum value of recorded axial stresses amounted to103.78 $\mathrm{MPa}$. The biggest change occurred after the tremor with the seismic energy of $3.7 \times 10^{6} \mathrm{~J}$ and amounted to $10.02 \mathrm{MPa}$. In addition, four events with the energy smaller than $1 \times 10^{5} \mathrm{~J}$ led to a significant change in stresses, i.e. $1.2 \times 10^{3} \mathrm{~J}(+7.53 \mathrm{MPa}) ; 5.0 \times 10^{3} \mathrm{~J}(+5.92 \mathrm{MPa}) ; 1.3 \times 10^{4} \mathrm{~J}(+6.83 \mathrm{MPa})$ and $5.0 \times 10^{2} \mathrm{~J}(+$ $4.92 \mathrm{MPa})$. The point cloud formed from the remaining 98 events did not reveal a clear correlation between their energy and the stress change within the roof strata. Figure 12 
shows that in many cases tremors with relatively low energies have a greater impact on the roof fall hazard than the high energy events.

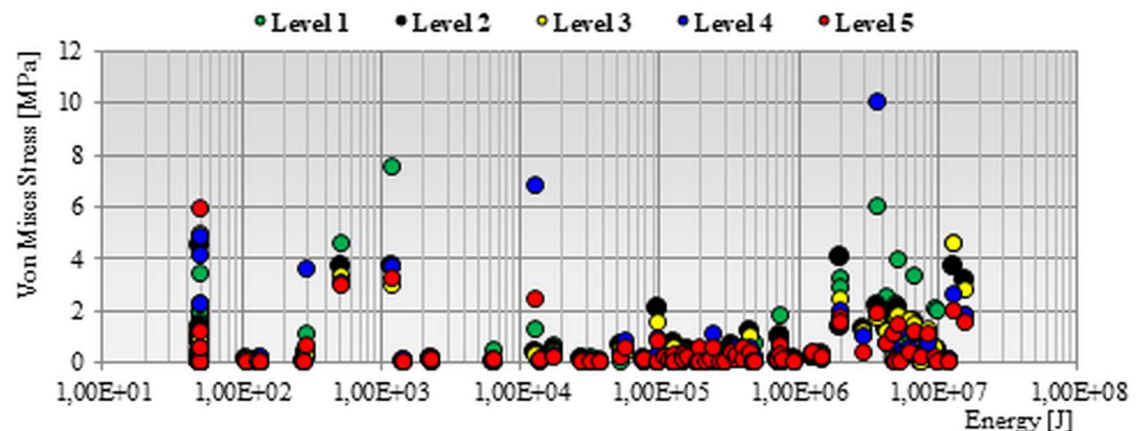

Fig. 12. Reduced stresses change due to dynamic event for bolt no. 1.

In the case of rock bolt no. 2 (Fig. 14), the maximum increase in the reduced stresses correlates with the occurrence of low-energy events. The highest stress increase was caused by a low-energy tremor of $1.1 \times 10^{2} \mathrm{~J}$. Additionally, a significant increase in stress ( $\left.52 \mathrm{MPa}\right)$ was observed right after the seismic event with the energy of $5.0 \times 10^{1} \mathrm{~J}$. Simultaneously, the negligible impact of high-energy events on the stress changes in the vicinity of the bolt no. 2 has been proven. This confirms the thesis that the roof fall safety is closely related to the location of tremors, even if they represent the lowest energy classes.

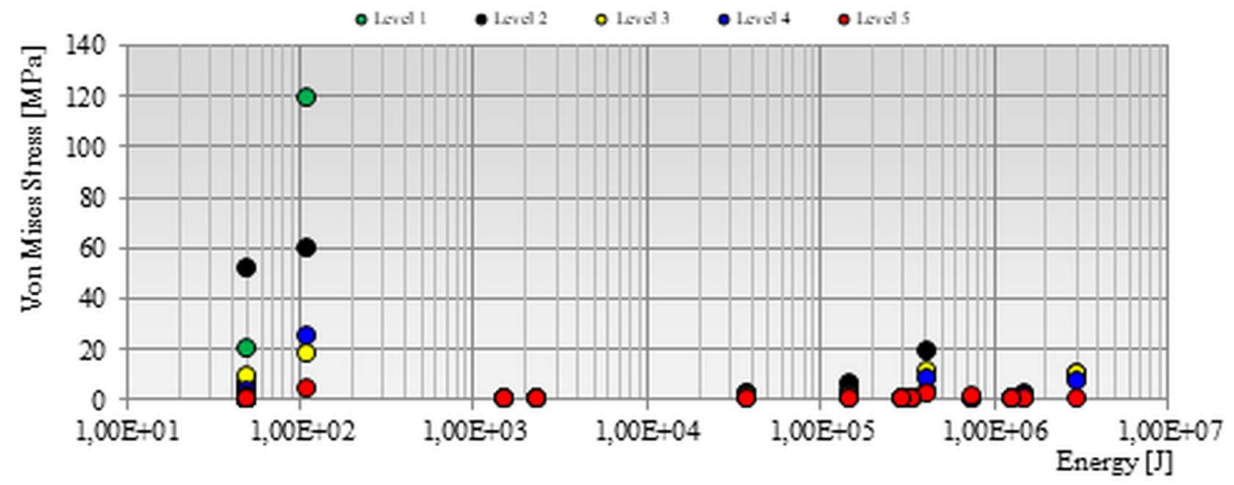

Fig. 13. Reduced stresses change due to dynamic event for bolt no. 2 .

In the roof strata in the vicinity of rock bolt no. 3 , the maximum stresses reduced based on von Mises criterion on the measurement completion day amounted to $40 \mathrm{MPa}$. Considering the impact of individual events on stress changes within the direct roof, it was concluded, that the greatest stress changes were caused by tremors of energy of $10^{4} \mathrm{~J}$ and $10^{5} \mathrm{~J}$, i.e. $1.5 \times 10^{5} \mathrm{~J}(+29 \mathrm{MPa}), 1.4 \times 10^{4} \mathrm{~J}(+26 \mathrm{MPa})$ and $1.3 \times 10^{5} \mathrm{~J}(-27 \mathrm{MPa})$. Events of E7 energy class did not cause any major stress changes in the roof strata in the vicinity of bolt no. 3. From figure 15 one may conclude, that the largest increase in stresses were recorded on the first measurement level, i.e. in the stratum located directly above the roof of the excavation. 


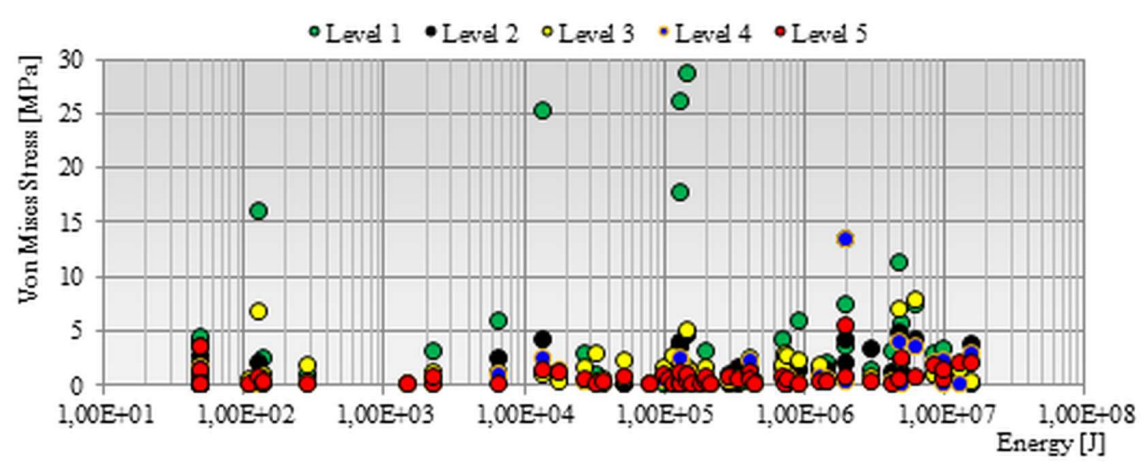

Fig. 14. Stresses change as a result of dynamic event for bolt no. 3 .

Changes of the stresses before and after the considered events were summed in order to determine the impact of events of particular energy classes on the stability of the roof. The obtained values are presented in spatial charts that enabled graphical interpretation of the obtained results. The largest total change in the stresses was caused by seismic events with energy of $1 \times 10^{6} \mathrm{~J}$ in the vicinity of bolt no. 1. Tremors of this type have a negative effect on the bolt rod along its entire length. Low-energy events had a significant effect on the stability of the roof as well (Fig. 15).

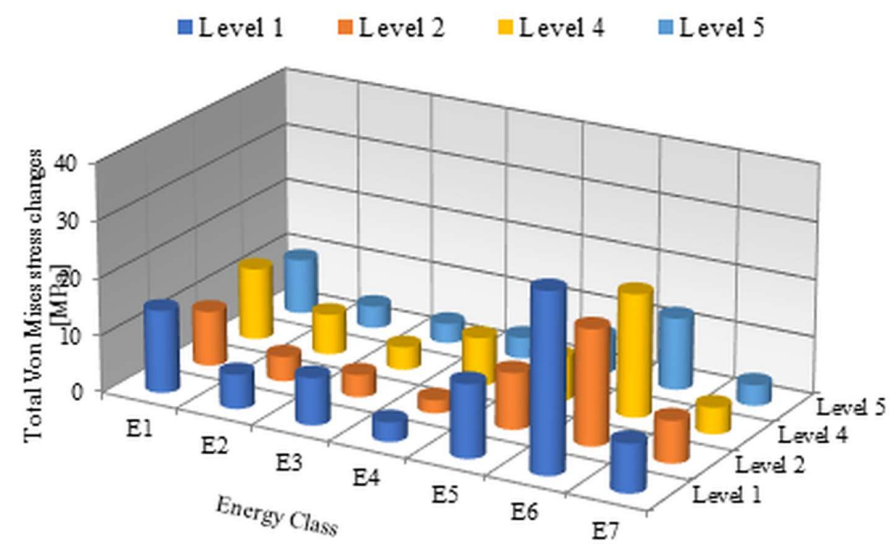

Fig. 15. Total changes of reduced stresses in bolt rod no. 1.

The largest stresses in bolt no. 2 were recorded at the first and second measurement level (Fig. 16). Changes of forces acting in the roof strata were triggered by events with low energy, i.e. E1 and E2 classes. It can therefore be assumed that such a high impact of tremors representing low energy classes is related to their genesis. Sudden increase of stresses in the area of measuring points after low-energy tremors indicates that they could have been caused by cracking or sudden spalling of rock stratum located directly above the immediate roof level. This confirms the increase in stresses at the first two measurement levels. Cracked rock layers, due to their low thickness, do not release energy great enough to determine their exact location during cracking. However, after partial detachment, they hang on the roof support generating high axial stresses. 


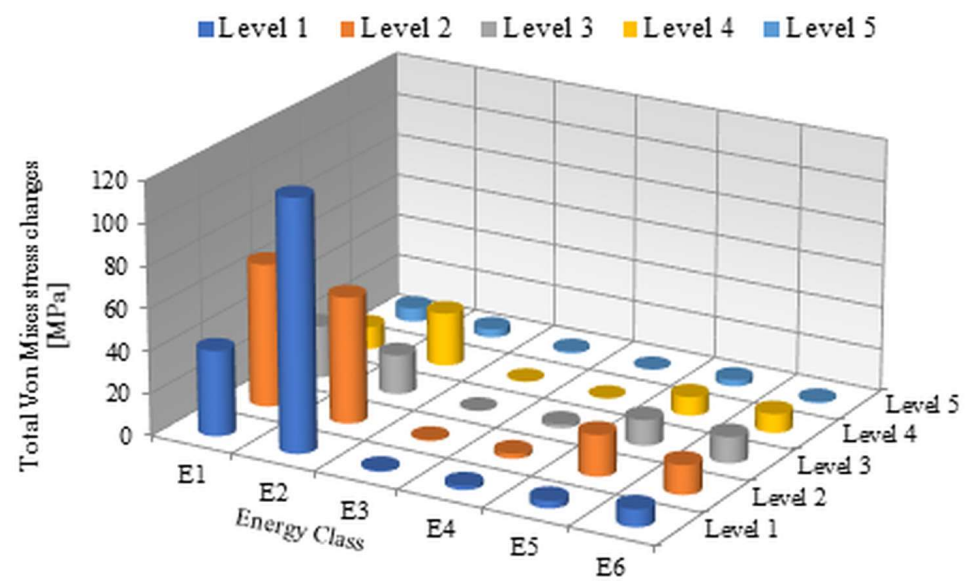

Fig. 16. Total changes of reduced stresses in bolt rod no. 2 .

Measurements in the rock bolt no. 3 were characterized by relatively small changes in stresses. As shown in Figure 17, many tremors resulted in a decrease in the stress acting on the bolt rod. Similarly as in the case of the other two measuring bolts, dynamic changes of reduced stresses were recorded at the first and second measurement level, i.e. directly above the bottom of immediate roof strata. However in this case, the greatest destructive impacts were associated with the high-energy tremors.

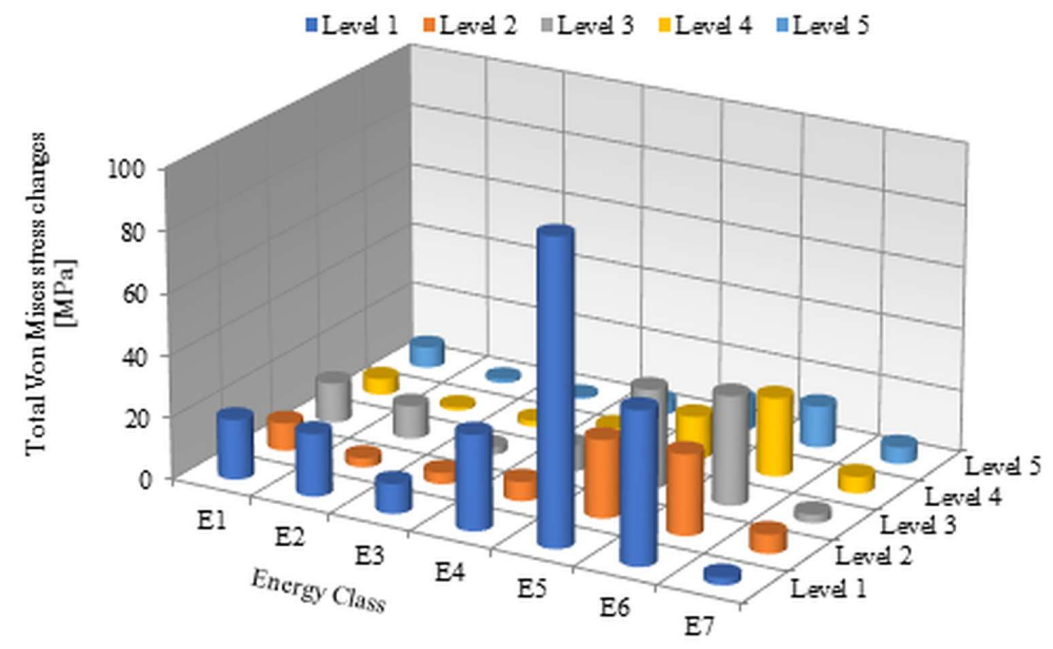

Fig. 17. Total changes in reduced stresses in the bolt no. 3 .

\section{Conclusions}

In the study, an analysis of the impact of the mining tremors recorded in the near-wave field on the stability of the direct roof in deep mine conditions was carried out. The calculations were obtained for 3 measuring rock bolts utilizing stress recordings of 103 tremors of different seismic energies. Statistical population included 60 phenomena of high-energy 
that were located at distances ranging from 51 to 346 meters from the measuring rock bolts and 43 events with energies lower than $10^{4} \mathrm{~J}$, mainly without a specific location of the tremor hypocentre. As the analysis indicates, the roof stratum near the measuring bolt no. 1 and 3 was not subjected to instability occurrence during the testing period. In the case of rock bolt no. 2, the load-bearing capacity was exceeded less than a month after the beginning of the observations. The emergency state of a roof fall hazard was observed a week before the actual roof fall. This clearly indicates that the application of instrumented rock bolts in excavations with a long-term use is justified as the stress recordings at several different levels allow to determine the degree of hazard, including the level where the instability may occur and which preventive roof falls measures may be undertaken.

Moreover, as a result of the performed analysis, the application of instrumented rock bolts in measurements of stability of the excavations was justified. The independent solution presented in this study indicates that the installation and maintenance of measuring rock bolts does not require a large amount of work, whereas the information obtained as a result of such measurements has an enormous value on the local condition of the roof support.

\section{References}

1. W. Korzeniowski, S. Piechota, Przegląd górniczy, 62:1, 12-16 (2006)

2. W. Korzeniowski, Górnictwo, 3, 161-174 (1994)

3. J. Butra, J. Kicki, Biblioteka Szkoły Eksploatacji Podziemnej (2012)

4. T. Majcherczyk, P. Małkowski, WUG, 29:3/2, 61-76 (2005)

5. C. Matusz, K. Szczerbiński, Cuprum, 1:66, 33-44 (2013)

6. T. Majcherczyk, P. Małkowski, Z. Niedbalski, Górnictwo i Geoinżynieria, 29:3/1, 289298 (2005)

7. S. Piechota, Przegląd Górniczy, 57:12, 25-29 (2001)

8. P. Małkowski, Z. Niedbalski, T. Majcherczyk, Górnictwo i Geoinżynieria, 32:1, 199215 (2008)

9. P. Małkowski, Wiadomości Górnicze, 65:5, 259-269 (2014)

10. J. Parchanowicz, S. Laskownicki, K. Szczerbiński, Cuprum, 19, 27-32 (2001)

11 W. Pytel, Proc. Aachen Int. Min. Symp., $425-441$ (2004)

12. S. Orzepowski, J. Butra, Rudy i metale nieżelazne, 56:2, 59-63 (2011)

13. S. Orzepowski, WUG, 9, 15-19 (2002)

14. K. Fuławka, P. Mertuszka, W. Pytel, E3S Web Conf., 29, 00008 (2018)

15. H. Mitri, Proc. Underground Coal Operators' Conference, 1, 136-140 (2011)

16. J. Butra, R. Dębkowski, D. Pawelus, M. Szpak, Cuprum, 1:58, 43-71 (2011)

17. J. Drzewiecki, Szkoła 2000, 2, 159-171 (2000),

18. J. Drzewiecki, Proc. Int. Symp. Rockbursts Seism. Min., 1, 351-354 (2001)

19. W. Pytel, P. Mertuszka, E. Fabiańczyk, K. Fuławka, Wiadomości Górnicze, 67:12, 654-664 (2016)

20. Guideline of roof strata classification (KGHM, Krakow, 2002) 